\title{
BIOCHEMICAL AND HEMATOLOGICAL PARAMETERS IN CHRONIC KIDNEY DISEASE
}

\author{
Singh $\mathrm{S}^{1^{*}}$, Bhatta $\mathrm{S}^{2}$ \\ ${ }^{1}$ Department of Biochemistry, KIST Medical College \\ ${ }^{2}$ Department of Pathology, KIST Medical College \\ *Corresponding Author: \\ Dr. Samir Singh, Associate Professor, Biochemistry, KIST Medical College, Lalitpur, E-mail: \\ samirbiochem.jnu@gmail.com.
}

\section{ABSTRACT}

Background: Chronic kidney disease is a worldwide public health problem. It is associated with various biochemical and hematological abnormalities that leads to morbidity and mortality. The aim of this study was to evaluate the biochemical and hematological parameters in chronic kidney disease patients.

Methods: This is a prospective cross sectional study conducted over a period of six months on 52 chronic kidney disease patients at Kist Medical College Teaching Hospital, Lalitpur, Nepal. Biochemical parameters such as urea, creatinine, calcium, phosphorous, sodium, potassium and hematological parameters like hemoglobin, hematocrit, red blood cell count, total leukocyte count, platelet count were measured using standard techniques in chronic kidney disease cases and the findings were compared with age and sex matched controls. Results were analyzed using SPSS 21 for Windows.

Results: Hemoglobin, hematocrit, red blood cell count, total leukocyte count and platelet count were reduced and statistically significant in chronic kidney disease patients compared to controls $(\mathrm{p}<0.05)$.In biochemical parameters, serum urea, creatinine, phosphorous were increased and calcium was reduced which was found statistically significant as compared to controls ( $\mathrm{p}$ $<0.05$ ). The combination of diabetes and hypertension was the lead cause of chronic kidney disease found in $38.46 \%$ followed by hypertension alone in $30.76 \%$

Conclusion: Biochemical and hematological parameters are deranged in patients with chronic kidney disease. Routine evaluation of these parameters is useful in the management of these patients.

Key words: Chronic kidney disease, Biochemical and hematological parameters, Creatinine, Hemoglobin

\section{INTRODUCTION}

Chronic kidney disease (CKD) is a spectrum of pathophysiologic processes associated with abnormal kidney function and a progressive decline in glomerular filtration rate (GFR). CKD is classified into five stages according to the estimated GFR. Chronic renal failure (CRF) is the irreversible reduction in nephron number which corresponds to CKD stages 3 to 5 . ${ }^{1}$ The estimated glomerular filtration rate (eGFR) for CKD is $<60 \mathrm{ml} / \mathrm{min} / 1.73 \mathrm{~m}^{2}$ for $>3$ months as 
defined by US National Kidney Foundation's Kidney Dialysis Outcomes Quality Initiative (K/DOQI) guideline. ${ }^{2}$ End stage renal disease (ESRD) is stage 5 CKD in which GFR is $<15$ $\mathrm{ml} / \mathrm{min} / 1.73 \mathrm{~m}^{2}$ and need renal replacement therapy or dialysis. 1,2

The major risk factors for CKD include hypertension, Diabetes mellitus and obesity. Biochemical and hematological parameters are affected in CKD and becomes more evident as the disease progresses. As the kidneys play a significant role in the regulation of body fluids, electrolytes and acid-base stability, CKD and ESRD predictably result in more than one derangements consisting of hyperkalemia, metabolic acidosis and hyperphosphatemia which, in turn result in severe complications such as bone-mineral disorders, muscle wasting, vascular calcification and mortality. Derangement in biochemical parameters as sodium, potassium, calcium, magnesium and chloride may be life threatening, hence these parameters should be kept within physiological range ${ }^{3-5}$

Various hematological parameters such as hemoglobin (Hb), hematocrit (Hct), Red blood cell (RBC) count, total leukocyte count (TLC) and platelet count are deranged in CKD. These alterations are due to marrow suppression by retained uremic products and aluminium toxicity associated with hemodialysis. Anemia in CKD is mostly due to reduced erythropoietin production from the kidney leading to decreased erythropoiesis. Other factors for anemia include hemolysis, chronic blood loss, nutritional deficiency, inflammation and hyperparathyroidism. ${ }^{6-8}$ The aim of this study was to evaluate the biochemical and hematological parameters in chronic kidney disease patients.

\section{MATERIALS AND METHODS}

This is a cross sectional observational study conducted in the departments of Biochemistry and Pathology at KIST Medical College over a period of six months from January to June 2018 which is ethically approved. A total of 52 patients of more than 20 years of age with serum creatinine $>1.5 \mathrm{mg} / \mathrm{dl}$ and documented CKD were included in the study. Fifty two age-sex matched healthy volunteers were taken as control. Patients with acute illness, bleeding disorders, pregnancy, chronic inflammatory diseases, hematological malignancy and serum creatinine $<1.5$ $\mathrm{mg} / \mathrm{dl}$ were excluded from the study. The patients were diagnosed based on KDOQI guidelines (CKD is defined as either kidney damage marked by albuminuria and GFR $<60 \mathrm{ml} / \mathrm{min} / 1.73 \mathrm{~m}^{2}$ for $>3$ months. Anemia is defined as hemoglobin level $<13 \mathrm{~g} / \mathrm{dl}$ in adult males and $12 \mathrm{~g} / \mathrm{dl}$ in adult females). ${ }^{2}$ Blood samples were collected in EDTA vacutainer for estimation of hematological parameters and plain vacutainer for estimation of biochemical parameters. The complete blood count was performed using an automated blood counter (Nihon Kohden CeltacES five part analyzer). Biochemical tests including sodium, potassium, phosphorus, calcium, urea and creatinine were tested in automated biochemistry analyzer (Siemens Dimension RxL Max).

Data were analyzed using Statistical Package for Social Science (SPSS, version 21) for Windows. Independent $t$ test was used for statistical analysis. $\mathrm{P}$ value less than 0.05 was considered as statistically significant.

RESULTS 
Out of 52 patients $30(57.6 \%)$ were male and $22(42.4 \%)$ were female with a male to female ratio of 1.36:1.The mean age of CKD patients was 51.21 \pm 14.12 years. Age of the patient ranged from 26-79 years. Majority of the patients were in the age group of 41-60 years (55.76\%) followed by $61-80$ years $(25 \%)$. Table 1

Table 1: Distribution of CKD patients according to age and gender

\begin{tabular}{l|l|l|l}
\hline Age $($ years $)$ & Male & Female & Total (\%) \\
\hline $\mathbf{2 1 - 4 0}$ & 8 & 2 & $10(19.24)$ \\
$\mathbf{4 1 - 6 0}$ & 15 & 14 & $29(55.76)$ \\
$\mathbf{6 1 - 8 0}$ & 7 & 6 & $13(25)$ \\
Total & 30 & 22 & $52(100)$ \\
\hline
\end{tabular}

The most common etiology for CKD was combination of hypertension and diabetes mellitus $(38.46 \%)$, followed by hypertension (30.76\%), diabetes mellitus (19.24\%), chronic glomerulonephritis $(5.76 \%)$, polycystic kidney disease $(3.85 \%)$ and renal stone with bilateral hydronephrosis $(1.93 \%)$ as shown in Fig 1

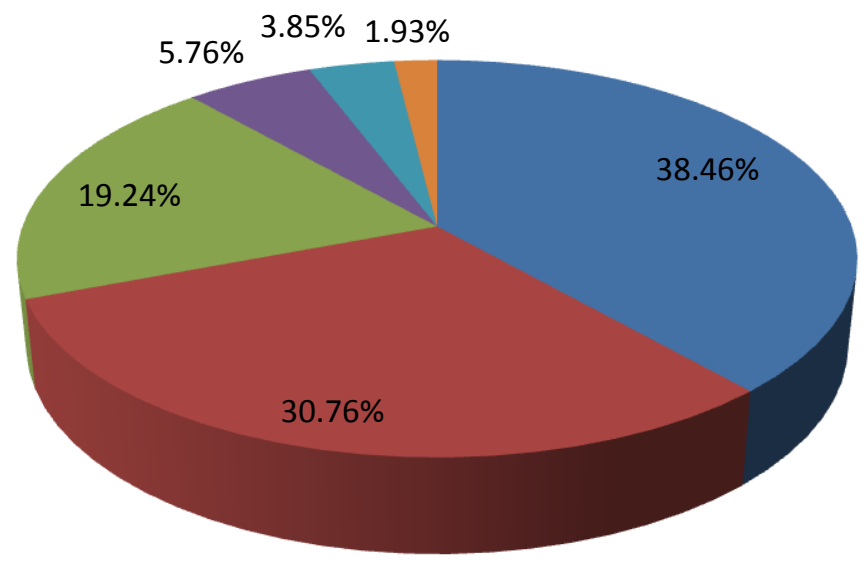

Hypertension and Diabetes
mellitus

- Hypertension

Diabetes mellitus

Chronic glomerulonephritis

Polycystic kidney disease

Renal stone with bilateral hydronephrosis

\section{Figure 1: Etiology of CKD}

The mean values of hemoglobin, hematocrit, red blood cell count, total leukocyte count and platelet count in patients with CKD were $8.61 \pm 1.59 \mathrm{gm} / \mathrm{dl}, 25.62 \pm 4.89 \%, 2.97 \pm 0.65$ million $/ \mathrm{mm}^{3}, 7457.69 \pm 1578.57$ thousands $/ \mathrm{mm}^{3}, 208926.92 \pm 69159.96$ lakhs/ $\mathrm{mm}^{3}$ respectively. All the hematological parameters were reduced in CKD patients compared to control group 
which was statistically significant $(\mathrm{p}<0.05)$. The mean values of urea, creatinine, sodium, potassium, calcium and phosphorous in CKD patients were $123.15 \pm 49.68 \mathrm{mg} / \mathrm{dl}, 6.68 \pm 3.55$ $\mathrm{mg} / \mathrm{dl}, \quad 135.37 \pm 9.44 \mathrm{mmol} / \mathrm{l}, \quad 4.31 \pm 0.95 \mathrm{mmol} / \mathrm{l}, \quad 8.03 \pm 0.80 \mathrm{mg} / \mathrm{dl}$ and $5.48 \pm 1.26 \mathrm{mg} / \mathrm{dl}$ respectively. Serum urea, creatinine and phosphorous were highly increased in CKD patients and calcium level was decreased as compared to control subjects which was statistically significant ( $\mathrm{p}<0.05)$. Serum potassium was increased and sodium was decreased in CKD patients as compared to controls but were not statistically significant. The biochemical and hematological parameters of CKD patients and control is shown in Table 2.

Table 2: Biochemical and Hematological parameters in CKD patients

\begin{tabular}{|c|c|c|c|}
\hline Parameters & CKD patients (Mean) & Control (Mean) & p value \\
\hline Creatinine (mg/dl) & $6.68 \pm 3.55$ & $0.76 \pm 0.28$ & $<0.001 *$ \\
\hline Urea (mg/dl) & $123.15 \pm 49.68$ & $24.40 \pm 8.46$ & $<0.001 *$ \\
\hline Sodium (mmol/l) & $135.37 \pm 9.44$ & $138.96 \pm 3.40$ & 0.193 \\
\hline Potassium (mmol/l) & $4.31 \pm 0.95$ & $4.08 \pm 0.48$ & 0.122 \\
\hline Calcium (mg/dl) & $8.03 \pm 0.80$ & $9.06 \pm 0.54$ & $<0.001 *$ \\
\hline Phosphorus (mg/dl) & $5.48 \pm 1.26$ & $4.26 \pm 0.51$ & $<0.001^{*}$ \\
\hline Hemoglobin (gm/dl) & $8.61 \pm 1.59$ & $13.93 \pm 1.14$ & $<0.001 *$ \\
\hline Hematocrit (\%) & $25.62 \pm 4.89$ & $41.17 \pm 3.67$ & $<0.001 *$ \\
\hline $\begin{array}{l}\text { Red blood cell count (Million/ } \\
\text { mm }^{3} \text { ) }\end{array}$ & $2.97 \pm 0.65$ & $4.63 \pm 0.45$ & $<0.001 *$ \\
\hline $\begin{array}{l}\text { Total leukocyte count } \\
\left.\text { (Thousands } / \mathrm{mm}^{3}\right)\end{array}$ & $7457.69 \pm 1578.57$ & $8234.62 \pm 1647.20$ & $0.016 *$ \\
\hline Platelet count (Lakhs/ mm ${ }^{3}$ ) & $208926.92 \pm 69159.96$ & $309730.77 \pm 77303.86$ & $<0.001 *$ \\
\hline
\end{tabular}

Note: * means significant $(p \leq 0.05=$ significant $)$

\section{DISCUSSION}

Chronic kidney disease is characterized by continuous reduction in glomerular filtration rate (GFR) that leads to accumulation of various nitrogenous metabolites in the blood including urea and creatinine. In this study, the mean level of urea and creatinine among study patients was $123.15 \pm 49.68 \mathrm{mg} / \mathrm{dl}$ and $6.68 \pm 3.55 \mathrm{mg} / \mathrm{dl}$ respectively which were significantly high $(\mathrm{p}<0.001)$ as compared to control. Similar study was done by Amin $\mathrm{N}$ et $\mathrm{al}^{9}$ and Khasawnah $\mathrm{N}$ et al ${ }^{10}$ in 
which they observed that urea and creatinine levels in patients with CKD were significantly elevated.

Creatinine is generated from creatine with the aid of non-enzymatic dehydration. Creatinine is synthesized in our body at a continuous manner and is excreted from our body through kidney glomerular filtration unit. Reduced kidney function can have an effect on the rate at which creatinine is filtered by means of the kidneys and may be used as a measure of kidney function. Due to inability of kidney to clear creatinine through urine excretion, kidney function deteriorates which results in increased levels of creatinine in blood serum. Urea is the major end product of protein catabolism in maximum animals and is produced in a sequence of reactions in the liver referred to as the urea cycle. In the urea cycle, ammonia is transformed to urea, which is carried by means of blood to the kidneys for its elimination from the body. Elevated levels of urea within the blood may additionally indicate renal failure. ${ }^{11}$ Accumulation of urea and creatinine concentrations in blood of CKD patients leads the body very un-wellness excreted from the blood streams through kidneys. ${ }^{12}$

Derangements of mineral metabolism begin early in the course of CKD and ESRD, and are typically observed by using profound changes in mineral metabolism that results in clinical issues which include bone illnesses, musculoskeletal problems and retardation of growth. Several studies has discovered a strong affiliation among mortality and abnormal mineral metabolism; probably mediated by vascular calcification. The disturbances embrace calcium, phosphorous, vitamin D, and PTH homeostasis. So, mineral metabolism results are gaining significance in hemodialysis treatment. ${ }^{13}$ In our study, the mean serum calcium in CKD subjects was $8.03 \pm 0.80$ and in controls was $9.06 \pm 0.54$ with $\mathrm{p}$ value $<0.001$ which was statistically significant. Majority of our study subjects were hypocalcemic.

Hypocalcemias because of hyperphosphatemia associated with $\mathrm{CKD}$, decrease in various calcium sensing receptors and fat soluble vitamin D receptor inside the parathyroid glands. Moreover, deficiency of 1, 25 dihydroxycholecalciferol or calcitriol, an active form of vitamin D that enables in absorption of dietary calcium from the intestine. ${ }^{14}$ Recent study done by ALHisnawi RAAA and Salih $\mathrm{H}^{15}$ observed significant hypocalcemia in patients with CKD as compared to controls. Freethi R et $\mathrm{al}^{16}$ also observed similar outcomes in their study and found significant hypocalcaemia in CKD patients $(9.8 \pm 0.45 \mathrm{mg} / \mathrm{dl})$ as compared to controls $(10.17 \pm 0.37 \mathrm{mg} / \mathrm{dl})$.

The mean serum phosphorous value of CKD patients in our study was $5.48 \pm 1.26$ and in controls was $4.26 \pm 0.51$ with $\mathrm{p}$ value $<0.001$ which was highly significant. This signifies the increased status of phosphorous i.e. hyperphosphatemia in CKD patients Hyperphosphatemia is one of the major factors liable for alterations in mineral and bone metabolism in dialysis patients. These findings are similar to the study done in Iran through Mahdavi-Mazdeh $\mathrm{M}$ et al ${ }^{17}$ and Singh $\mathrm{S}$ et $\mathrm{al}^{13}$ in Nepal. Hyperphosphatemia results due to reduced phosphorous filtration and excretion with the progression of CKD.

The kidneys play a central role in maintaining the phosphorous homeostasis by proper excretion of phosphorus through the urine in response to its high levels to make certain that their serum concentrations are good enough for the performance of numerous functions. Decreased GFR will increase serum phosphorus levels as its excretion will be reduced. ${ }^{18}$ 
In the present study, the mean value of serum sodium and potassium in cases were $135.37 \pm 9.44$ $\mathrm{mmol} / \mathrm{l}$ and $4.31 \pm 0.95 \mathrm{mmol} / \mathrm{l}$ respectively. The mean value of serum sodium and potassium in controls were $138.96 \pm 3.40 \mathrm{mmol} / \mathrm{l}$ and $4.08 \pm 0.48 \mathrm{mmol} / \mathrm{l}$ respectively. Although serum potassium was increased and sodium was decreased they were statistically insignificant. Estimation of electrolytes should be frequently completed in CKD patients to avoid delay in correction of dysnatremias which might also cause serious complications and increase the frequency of morbidity and mortality among CKD patients. ${ }^{14}$ AL-Hisnawi RAAA and Salih $\mathrm{H}^{15}$ in their study located statistically nonsignificant decreased in serum sodium inside the CKD patients as compared to controls.

As we are aware of the fact that the kidneys are principally responsible for the maintenance of fluid and electrolyte balance, acute or chronic changes in renal function can result in various imbalances. Severely, the rapidity of beginning of renal deterioration makes nursing evaluation and intervention critical to the prevention of complications and potentially fatal outcomes. In acute or chronic renal failure patients have a tendency to develop hypervolemia, hyperkalemia, hyperphosphatemia, hypocalcemia, and metabolic acidosis. Sodium is generally retained, but may appear normal, or hyponatremic, because of dilution from fluid retention. ${ }^{5}$

Our data showed the combination of diabetes and hypertension in the main lead among the risk factors of CKD followed by hypertension, chronic glomerulonephritis, polycystic kidney disease, and others which is concordant with data from a study conducted by Singh S et al ${ }^{19}$ who reported that diabetic nephropathy is the leading cause of ESRD worldwide.

In our study red blood cell parameters as $\mathrm{Hb}$, Hct, RBC count were reduced and statistically significant $(\mathrm{p}<0.001)$ when compared to controls. This finding was in agreement with other studies. ${ }^{20,21}$ The major factor for reduction of these red blood cell parameters is impaired erythropoietin production along with other factors that suppress marrow erythropoiesis and shortened red cell survival. ${ }^{6-8}$ Erythropoietin is the hormone which regulates red blood cell production and maintain the viability of RBC by retarding the cleavage of DNA. In the absence of erythropoietin, DNA cleavage is rapid and leads to cell death. In CKD due to impaired production of erythropoietin and destruction of red cells $\mathrm{Hb}$ and Hct concentration fall which is evident even in patients with mild to moderate renal insufficiency. ${ }^{22}$ Erythropoietin also potentiates the effect of megakaryocyte colony stimulating factors, acetylhydrolase (PAF-AH) and paraoxonase (PON 1). Hence in CKD impaired erythropoietin production leads to reduction in platelet count. ${ }^{23}$ In the present study platelet count was reduced and statistically significant ( $p<0.001)$. Similar results have been found in various other studies. ${ }^{20,21,24,25}$

Total leukocyte count in our study was reduced and statistically significant $(\mathrm{p}=0.016)$. Reduction in TLC in CKD patients undergoing dialysis is due to complement activation which induces neutrophil aggregation and adherence to endothelial surface. ${ }^{26}$ Suresh $\mathrm{M}$ et al. $^{20}$ showed decreased TLC in their study similar to our study but it was not statistically significant. Other study showed increase in total leukocyte count in CKD patients. ${ }^{21}$

\section{CONCLUSION}


CKD is associated with derangement in various biochemical and hematological parameters. Regular evaluation of such parameters in CKD patients is mandatory. Correction of these abnormalities help to reduce the morbidity and mortality related to CKD.

\section{CONFLICT OF INTEREST}

We declare no conflict of interest

\section{REFERENCES}

1. Bargman JM, Skorecki K. Chronic Kidney Disease. In: Harrison's Principles of Internal Medicine. $18^{\text {th }}$ ed. New York: McGraw-Hill; 2012: P2308.

2. National Kidney Foundation. K/DOQI clinical practice guidelines for chronic kidney disease: evaluation, classification and stratification. Am J Kidney Dis. 2002; 39: 1266.

3. Hossain MDS, Akter-Uz-Zaman KMD, Amin MN, Ahammed R, Haque MDE, Ibrahim MD et al. Association of biochemical parameters with renal functions of end stage renal disease (ESRD) patients of Bangladesh. J Bioanal Biomed. 2017; 9: 294298.

4. Latiwesh OB, Elwerfally HH, Sheriff DS, Younis MYG. Hematological changes in predialyzed and hemodialyzed chronic kidney disease patients in Libya. IOSR Journal of Dental and Medical Sciences (IOSR-JDMS). 2017; 16: 106-112.

5. Chambers JK. Fluid and electrolyte issues in renal and urologic disorders. Nurs Clin North Am. 1987; 22(4): 815-826.

6. Hsu CY, Bates DW, Kuperman GJ, Curhan GC. Relationship between hematocrit and renal function in men and women. Kidney International. 2001; 59: 725-731.

7. Locatelli F, Pozzoni P, Del VL. Recombinant Human Epoietin beta in the treatment of renal anemia. Ther Clin Risk Manag. 2007; 3: 433-439.

8. Katz I. Kidney and kidney related chronic diseases in South Africa and chronic disease intervention program experiences. Advances in chronic kidney disease. 2005; 12: 14-21.

9. Amin N, Mahmood RT, Asad MJ, Zafar M,and Raja AM. Evaluating urea and creatinine levels in chronic renal failure pre and post dialysis: a prospective study. JCVD. 2014; 2(4): 182-185.

10. Khasawnah N, Alrahman Abu Abeeleh JA. Hematological and biochemical findings among Jordanian patient with end stage renal disease. European Scientific Journal. 2015; 11(3): 135-140.

11. Merzah KS, Hasson SF. The Biochemical Changes in Patients with Chronic Renal Failure. Int J Pharm Med Biol Sci. 2015; 4: 75-79.

12. Nisha R, Srinivasa Kannan SR, Thanga Mariappan K. Biochemical evaluation of creatinine and urea in patients with renal failure undergoing hemodialysis. J Clin Path Lab Med. 2017; 1(2): 1-5. 
13. Singh S, Upadhyay DK, Aryal G. Value of Calcium and Phosphorous in chronic kidney disease patients under hemodialysis: A retrospective study. Journal of Pathology of Nepal. 2012; 2: 293-296.

14. Phukan RR, Goswami RK. A study of serum sodium and calcium status in both hemodialysed and conservatively treated chronic kidney disease patients attending a tertiary care hospital of Assam, India. Int J Res Med Sci 2016; 4(12): 5405-5410.

15. AL-Hisnawi RAAA, Salih H. A study of some biochemical changes in patients with chronic renal failure undergoing hemodialysis. Int J Curr Microbiol App Sci. 2014; 3(5): 581-586.

16. Freethi R, Raj AV, Ponniraivan K, Khan MR, Sundhararajan A, Venkatesan. Study of serum levels of calcium, phosphorus and alkaline phosphatase in chronic kidney disease. Int J Med Res Health Sci 2016. 5(3): 49-56.

17. Mahdavi MM, Zamyadi M, Norouzi S, Heidary RA. Management of Calcium and Phosphorus Metabolism in Hemodialysis Patients in Tehran Province, Iran. Iran J Kidney Dis. 2007; 1: 25-28.

18. García CA, Cielo HM, Cáceres ED, Restrepo CA. Importance of hyperphosphatemia in chronic kidney disease, how to avoid it and treat it by nutritional measures. Rev. Colomb. Nefrol. 2017; 4(1): 24-41.

19. Singh S, Verma A, Aryal G, Thapa S, Khakurel S, Shrestha K. Thyroid hormone profile in patients with chronic kidney disease: a single centre study. J Nepal Health Res Counc. 2016; 14(34): 197-201.

20. Suresh M, Mallikarjuna RN, Sharan B, Singh M, Hari KB, Shravya KG et al. Hematological changes in chronic renal failure. Int J Sci Res Publ. 2012; 2: 1-4.

21. Habib A, Ahmad R, Rehman S. Hematological changes in patients of chronic renal failure and the effect of hemodialysis on these parameters. Int J Res Med Sci. 2017; 5: 4998-5003.

22. Dessypris EN, Sawyer ST. Erythropoiesis. In: Greer JP, Foerster J, Rodgers GM, Paraskevas F, Glader B, Arber DA. Wintrobe's Clinical Hematology. $12^{\text {th }}$ ed. Philadelphia: Lippincott Williams and Wilkins; 2009: P120.

23. Papavasiliou EC, Gouva C, Siamopoulos KC, Tselepis AD. PAF-acetylhydrolase activity in plasma of patients with chronic kidney disease. Effect of long-term therapy with erythropoietin. Nephrol dial transplant. 2006; 21: 1270-77.

24. Yassein RB, Alseedig NO, Abdallah SK, Mohammed AA, Alballah NA, Syid MA. Hematological parameters among Sudanese patients with chronic renal failure. Internat J Res Granthaalayah. 2016; 4: 50-4.

25. Alghythan AK, Alsaeed AH. Hematological changes before and after hemodialysis. Sci. Res. Essays. 2013; 7: 490-7.

26. Watts RG. Neutropenia. In: Greer JP, Foerster J, Rodgers GM, Paraskevas F, Glader B, Arber DA. Wintrobe's Clinical Hematology. $12^{\text {th }}$ ed. Philadelphia: Lippincott Williams and Wilkins; 2009: P1532. 